\title{
BMJ Open Physician staffed emergency medical service for children: a retrospective population-based registry cohort study in Odense region, Southern Denmark
}

\author{
Morten Føhrby Overgaard (D , , ${ }^{1,2}$ Anssi Heino, ${ }^{3}$ Sofie Allerød Andersen, ${ }^{1}$ \\ Owain Thomas, ${ }^{4,5}$ Johan Holmén, ${ }^{6}$ Søren Mikkelsen (iD) 1,7,8
}

To cite: Overgaard MF, Heino A, Andersen SA, et al. Physician staffed emergency medical service for children: a retrospective populationbased registry cohort study in Odense region, Southern Denmark. BMJ Open 2020;10:e037567. doi:10.1136/ bmjopen-2020-037567

- Prepublication history for this paper is available online. To view these files, please visit the journal online (http://dx.doi org/10.1136/bmjopen-2020037567).

Received 07 April 2020 Revised 25 June 2020 Accepted 02 July 2020

Check for updates

(C) Author(s) (or their employer(s)) 2020. Re-use permitted under CC BY-NC. No commercial re-use. See rights and permissions. Published by BMJ.

For numbered affiliations see end of article.

Correspondence to Dr Morten Føhrby Overgaard; morten.overgaard@rsyd.dk

\section{ABSTRACT}

Objectives The aim of this study is to determine diagnostic patterns in the prehospital paediatric population, age distribution, the level of monitoring and the treatment initiated in the prehospital paediatric case. Hypothesis was that advanced prehospital interventions are rare in the paediatric patient population.

Setting We performed a retrospective population-based registry cohort study of children attended by a physicianstaffed emergency medical service (EMS) unit (P-EMS), in the Odense area of Denmark during a 10-year study period.

Participants We screened 44882 EMS contacts and included 5043 children. Patient characteristics, monitoring and interventions performed by the P-EMS crews were determined.

Results We found that paediatric patients were a minority among patients attended by P-EMS units: 11.2\% (10.9 to 11.5$)(95 \% \mathrm{Cl})$ of patients were children. The majority of the children were $<5$ years old; one-third being $<2$ years old. Respiratory problems, traffic accidents and febrile seizures were the three most common dispatch codes. Oxygen supplementation, intravenous access and application of a cervical collar were the three most common interventions. Oxygen saturation and heart rate were documented in more than half of the cases, but more than one-third of the children had no vital parameters documented. Only $22 \%$ of the children had respiratory rate, saturation, heart rate and blood pressure documented. Prehospital invasive procedures such as tracheal intubation $(n=74)$, intraosseous access $(n=22)$ and chest drainage $(\mathrm{n}=2)$ were infrequently performed. Conclusion Prehospital paediatric contacts are uncommon, more frequently involving smaller children. Monitoring or at least documentation of basic vital parameters is infrequent and may be an area for improvement. Advanced and potentially life-saving prehospital interventions provide a dilemma since these likely occur too infrequently to allow service providers to maintain their technical skills working solely in the prehospital environment.

\section{INTRODUCTION}

Various aspects of emergency medical events have previously been examined in
Strengths and limitations of this study

- This is a retrospective and observational study, and conclusions on causal relationships between study parameters must be made with caution.

- A considerable weakness of the study is that there is no formal validation of a subjective measure of outcome.

- The study does not present follow-up data on morbidity or mortality following admission to hospital.

- The study presents data from single geographical area with relatively short response times, and comparison with other prehospital systems must be done with caution.

Scandinavian studies. Little attention has; however, been paid to paediatric patients, ${ }^{1-8}$ which is unfortunate since robust paediatric prehospital emergency data may allow evaluation of the adequacy of prehospital responses to paediatric emergencies, improvements in the preparation and training of prehospital personnel for paediatric medical issues and prioritisation of future research in this field.

In recent years it has been elucidated that 'complications in paediatric anaesthesia are directly related to the (in) experience of the anaesthesiologist in charge'. 9 This has led to the emergence of the concept of '10-N-Quality Paediatric Anaesthesia', and the 'Safe Anaesthesia For Every Tot' initiative which aims to define the safe conduct of paediatric anaesthesia. ${ }^{10}$ No such initiative exists for prehospital paediatric patients, and the role of the anaesthesiologist in the prehospital setting varies from region to region and country to country. Although the prehospital environment is less controlled than the operating room, several parallels can be drawn with regards to a systematic approach to both the safe conduct of paediatric anaesthesia and the prehospital paediatric case. 
The aim of this study was to determine diagnostic patterns in the prehospital paediatric population, age distribution, the level of monitoring and the treatment initiated in the prehospital paediatric case. The hypothesis was that advanced prehospital interventions are rare in the paediatric patient population.

\section{METHODS}

\section{Study design}

We performed a retrospective population-based registry cohort study paediatric medical emergency calls managed by the Emergency Medical Dispatch Centre, EMDC, in the Region of Southern Denmark from October 2007 to December 2017.

\section{Study setting and selection of patients}

We performed a registry-based follow-up study of patients attended by a physician staffed land unit after emergency calls. All patients 18 years or less, who were attended to by a physician-manned emergency medical service (EMS) unit between the dates of 1 October 2007 and 31 December 2017 were included.

\section{Study Setting}

The study was carried out in the Mobile Emergency Care Unit (MECU) in Odense in the Region of Southern Denmark. The MECU in Odense is a part of the nationally implemented and publicly funded three-tiered emergency medical system in which the basic resource is an ambulance manned with two emergency medical technicians. The MECU in Odense is an anaesthesiologist-manned rapid-response vehicle consisting of an anaesthesiologist and an emergency medical technician supplementing the ordinary ambulances. Danish physician-staffed EMS (P-EMS) units are staffed with senior anaesthesia and intensive care registrars or consultants who work as part time prehospital physicians. It covers a population of approximately 260000 people living within $2500 \mathrm{~km}^{2}{ }^{211}$

The EMDC responds to calls for assistance from all the Region of Southern Denmark. Thus, it covers a population of 1210000 people in both rural and urban areas. Following calls from the public, the EMDC dispatches either an ambulance, an ambulance and a paramedic or an ambulance and a P-EMS unit. For patients younger than 3 years of age a P-EMS is automatically dispatched irrespective of severity. ${ }^{12}$

\section{Data collection}

The following data were obtained: age and gender of the patient, dispatch code from the dispatch centre, response time, pharmacological and non-pharmacological interventions performed by the prehospital staff, number and types of monitoring modalities, initial evaluation of the severity of the case and the preliminary diagnosis assigned to the patient by the prehospital physician (according to the WHO International Classification of Diseases-10 classification system). Interventions were labelled as either basic or advanced. Advanced interventions were defined as interventions exceeding the curriculum of either the emergency medical technician or paramedic. Rate of intervention was defined as a patient receiving one or more interventions.

\section{Exclusion criteria}

Patients attended, but whose age or identification details were unknown were excluded.

\section{Patient and public involvement}

No patients or the public were involved in either the planning or design of the study.

\section{RESULTS}

The study period included 44882 patient contacts, of which 5240 were patients 18 years or less. In the study database, unidentified patients were registered with a birthdate that was the P-EMS contact date, thus resulting in unidentified contacts being labelled as paediatric patients. Since the real age of these unidentified patients could not be confirmed, they were excluded from the study. This represents an issue with patients born on day of the contact. These patients were likely to be few but would be the result of unexpected or precipitous delivery. These could be premature but viable neonates that would require advanced interventions. Dispatch codes likely to result in newborns were: 'delivery' $n=4$, 'newborn' $n=1$, 'prematurity' $n=1$. However, the database does not permit to distinguish between mother and child, and due to the very low numbers, these contacts were left out of analysis. The total number of these unidentified patients was 197 .

Final analysis was carried out in 5043 paediatric cases, amounting to $11.2 \%$ (10.9 to 11.5 ) of all contacts (figure 1). Data in tables are presented as absolute numbers, in percentages of the total number of observations and with $95 \%$ CIs.

The median (IQR) age of the prehospital paediatric patient was 4 years (1-14 years). Male gender was predominant, the overall M:F ratio being 1.18, seen most clearly in the younger age groups (figure 2). Median (IQR) response time from dispatch to first patient contact was $7 \mathrm{~min}$ (5-11 $\mathrm{min})$. Since many patients were either discharged at site or admitted to hospital without priority transportation without an accompanying physician, time to admission was difficult to interpret and hence omitted from analysis.

One or more vital parameters, that is, blood pressure, pulse rate, saturation and respiration frequency-were recorded in $62.5 \%$ of patients (figure 1 ). Oxygen saturation was measured most often, in 57\% of all cases. Only $22.0 \%$ had all four vital parameters recorded.

The most common intervention overall was oxygen administration $(\mathrm{n}=1492)$ which was performed in $29.6 \%$ (28.3 to 30.9) of all contacts. Intravenous access was the most common advanced intervention $(\mathrm{n}=1041)$ and was performed in $20.6 \%$ (19.5 to 21.8) of all paediatric cases. 


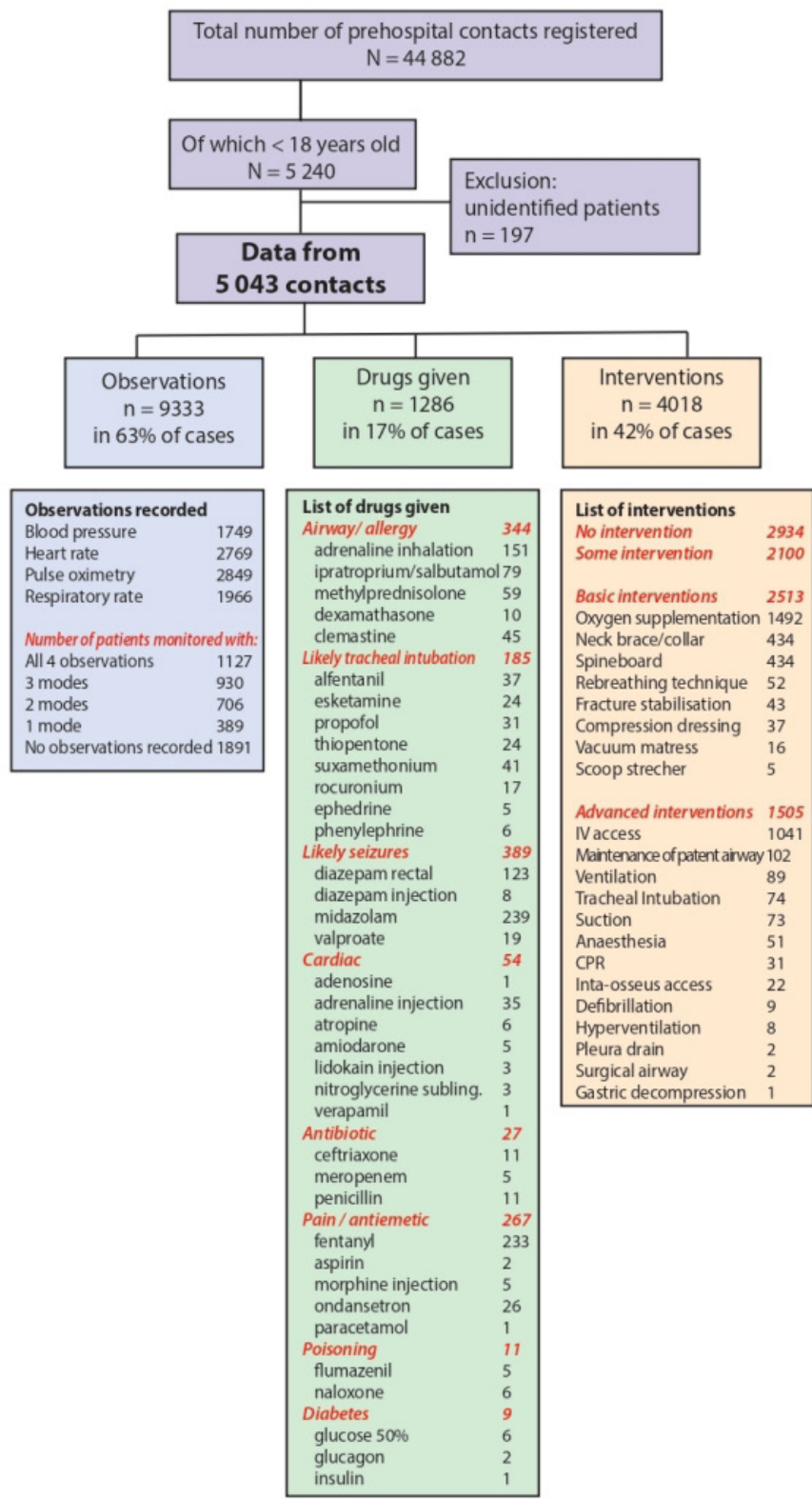

Figure 1 Paediatric prehospital interventions. CPR, cardiopulmonary resuscitation.

Overall rate of any intervention was $41.6 \%$ (40.6 to 43.0) and rate of advanced intervention was in $21 \%$ (19.9 to 22.1).

During the 10-year follow-up intubation was performed a total of 74 times, overall rate being $1.5 \%$. The rate by age group for intubation was similar to the age distribution for the paediatric patients in general. Intubation was performed 21 times for children younger than 2 years, and 18 times for patients aged 17 and 18 . The incidence of cardiopulmonary resuscitation was similarly low. Cardiopulmonary resuscitation (CPR) was performed 31 times, the overall rate being $0.6 \%$. Primary rhythm analysis was registered as asystole $n=19$; ventricular fibrillation $n=4$; ventricular tachycardia $n=3$; other $n=5$. Only $17 \%$ were given medication: midazolam and fentanyl were the most frequently administered drugs.

\begin{tabular}{lrl}
\hline Table 1 Dispatch codes & & \\
\hline Dispatch code & N & \% (95\% Cl) \\
\hline Breathing difficulties & 840 & $16.7(15.6$ to 17.7$)$ \\
\hline Traffic accident & 721 & $14.3(13.3$ to 15.3$)$ \\
\hline Febrile convulsions & 704 & $14.0(13.0$ to 14.9$)$ \\
\hline Injury, unspecified & 678 & $13.4(12.5$ to 14.4$)$ \\
\hline Unspecified disease & 636 & $12.6(11.7$ to 13.6$)$ \\
\hline Convulsions & 635 & $12.6(11.7$ to 13.5$)$ \\
\hline Unconsciousness & 294 & $5.8(5.2$ to 6.5$)$ \\
\hline Foreign body in airways & 92 & $1.8(1.5$ to 2.2$)$ \\
\hline Poisoning & 81 & $1.6(1.3$ to 2.0$)$ \\
\hline Asthma & 72 & $1.4(1.1$ to 1.8$)$ \\
\hline Cardiac disease & 56 & $1.1(0.8$ to 1.4$)$ \\
\hline Allergy & 46 & $0.9(0.7$ to 1.2$)$ \\
\hline Fall from heights & 36 & $0.7(0.5$ to 1.0$)$ \\
\hline Diabetes & 30 & $0.6(0.4$ to 0.8$)$ \\
\hline Meningitis & 24 & $0.5(0.3$ to 0.7$)$ \\
\hline Cardiac arrest & 22 & $0.4(0.3$ to 0.7$)$ \\
\hline Unspecified bleeding & 21 & $0.4(0.3$ to 0.6$)$ \\
\hline Major burns & 20 & $0.4(0.2$ to 0.6$)$ \\
\hline Not classified & 35 & $0.7(0.5$ to 1.0$)$ \\
\hline Total & 5043 & 100 \\
\hline & & \\
\hline
\end{tabular}

The three most common emergency dispatch codes were: breathing difficulties, need for transportation and febrile seizures (table 1). Critical dispatch codes were relatively infrequent: airway obstruction $(\mathrm{n}=94)$, meningitis $(n=24)$, cardiac arrest $(n=22)$, major burn injury $(n=20)$.

The three most common diagnoses registered by EMS physicians were: febrile seizure, observation after traffic accident and 'observation for suspected disease' (table 2). Critical diagnoses were infrequent and discrepancies when comparing with the dispatch codes were noted: foreign body airway obstruction $(n=97)$, cardiac arrest $(n=13)$, bacterial meningitis $(n=11)$.

Most of the paediatric patients in this study were transported from scene to hospital and most of these

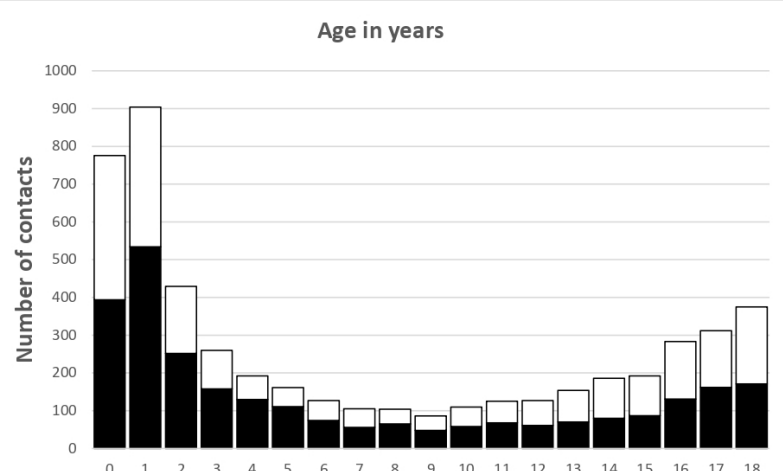

Figure 2 Age distribution of paediatric prehospital patients. 


\begin{tabular}{|c|c|c|c|}
\hline ICD 10 code & Diagnosis & $\mathbf{N}$ & $\%(95 \% \mathrm{Cl})$ \\
\hline R56.0 & Febrile convulsions & 935 & 18.5 (17.5 to 19.6$)$ \\
\hline Z04.1 & Examination and observation following transport accident & 623 & 12.3 (11.5 to 13.3$)$ \\
\hline Z03.9 & Observation for suspected disease or condition, unspecified & 403 & 8.0 (7.3 to 8.8$)$ \\
\hline R56.8 & Other and unspecified convulsions & 368 & $7.3(6.6$ to 8.1$)$ \\
\hline Z04.3 & Examination and observation following other accident & 346 & $6.9(6.2$ to 7.6$)$ \\
\hline Z04.8 & Examination and observation for other specified reasons & 278 & 5.5 (4.9 to 6.2$)$ \\
\hline J05 & Acute obstructive laryngitis (croup) and epiglottitis & 248 & $4.9(4.3$ to 5.6$)$ \\
\hline R50.9 & Fever, unspecified & 190 & $3.8(2.7$ to 4.3$)$ \\
\hline G40.9 & Epilepsy, unspecified & 167 & 3.3 (2.8 to 3.8$)$ \\
\hline R06.4 & Hyperventilation & 118 & 2.3 (1.9 to 2.8$)$ \\
\hline S06.0 & Concussion & 108 & 2.1 (1.8 to 2.6$)$ \\
\hline J96.9 & Respiratory failure, unspecified & 106 & 2.1 (1.8 to 2.5$)$ \\
\hline R55.9 & Syncope and collapse & 105 & 2.1 (1.8 to 2.5$)$ \\
\hline $\mathrm{T} 17.9$ & Foreign body in respiratory tract, part unspecified & 97 & 1.9 (1.6 to 2.3 ) \\
\hline T78.4 & Allergy, unspecified & 80 & $1.6(1.3$ to 2.0$)$ \\
\hline T07.9 & Unspecified multiple injuries & 79 & $1.6(1.2$ to 1.9$)$ \\
\hline $\mathrm{J} 45.9$ & Asthma, unspecified & 76 & $1.5(1.2$ to 1.9$)$ \\
\hline J18.9 & Pneumonia, unspecified & 52 & $1.0(0.8$ to 1.4$)$ \\
\hline $\mathrm{T} 14.0$ & Superficial injury of unspecified body region & 44 & $0.9(0.6$ to 1.1$)$ \\
\hline \multirow[t]{2}{*}{ T12.9 } & Fracture of lower limb, level unspecified & 42 & $0.8(0.6$ to 1.1$)$ \\
\hline & Other diagnoses & 578 & 11.5 (10.6 to 12.4 ) \\
\hline Total & & 5043 & 100 \\
\hline
\end{tabular}

ICD, International Classification of Diseases.

transportations were carried out without a physician's escort (table 3). As many as $17 \%$ of the patients were treated and subsequently discharged at the scene and thus required no transportation.

In the study database, clinical outcome is registered for each patient treated by the P-EMS (table 3). Most of the patients were scored as either 'status unchanged' or 'some improvement'. Approximately $10 \%$ of all cases were labelled with either 'significant improvement' or 'lifesaving'. Only about $1 \%$ of the patients were labelled 'deteriorating' or 'death'.

\section{DISCUSSION}

Prehospital paediatric contacts are uncommon. More frequently they involve smaller children. Most contacts took place with children under 5 years of age, and a clear peak was seen with children less than 2 years of age. Monitoring of vital parameters was applied to approximately two-thirds of all cases, and measurement of oxygen saturation was the most common monitoring procedure carried out. The most common interventions were oxygen supplementation and intravenous access. Other than intravenous access, advanced interventions such as intubation, CPR, intraosseous access and pleural drainage were rare.
In this study, $11.2 \%$ of all patient contacts concerned patients 18 years old or younger. This is similar to other existing studies, ${ }^{6-8}$ where the rate of paediatric contacts has been reported to be between $5 \%$ and $7 \%$. The slightly higher percentage in this study may be explained by the fact that our EMDC protocol sends a P-EMS to all children less than 3 years of age, irrespective of severity. This dispatch policy is likely to partly explain the low intervention rate per patient contact for children and probably explains the high number of febrile convulsions in the data set.

Healthcare workers often find caring for children to be more stressful than caring for adults. ${ }^{13} 14$ However, most of the children in this study recovered spontaneously or with minor assistance. In addition to the infrequency of children in the prehospital setting, the low incidence of advanced interventions other than intravenous access performed in paediatric patients is striking. Paediatric CPR is rare $^{1516}$ and in this study, it was conducted only for 31 patients. Paediatric cardiac arrest is most often caused by hypoxia, compared with cardiac reasons in adult patients, ${ }^{1617}$ and findings of this study support this: only nine patients received defibrillation, presumably due to the rhythm being asystole rather than ventricular arrhythmia. These findings of advanced interventions 
Table 3 Prehospital mission outcome and status at completion of mission

\begin{tabular}{|c|c|c|}
\hline Mission outcome & $\mathbf{N}$ & $\%(95 \% \mathrm{Cl})$ \\
\hline $\begin{array}{l}\text { Transported to hospital } \\
\text { without physician escort }\end{array}$ & 3092 & $61.3(60.0$ to 62.7$)$ \\
\hline $\begin{array}{l}\text { Transported to hospital with } \\
\text { physician escort }\end{array}$ & 1078 & 21.4 (20.3 to 22.5$)$ \\
\hline $\begin{array}{l}\text { Released at the scene } \\
\text { following treatment }\end{array}$ & 743 & $14.7(13.8$ to 15.7$)$ \\
\hline Mission down-prioritised & 70 & $13.9(10.8$ to 17.5$)$ \\
\hline $\begin{array}{l}\text { Miscellaneous (telephone } \\
\text { consultation, administrative } \\
\text { tasks) }\end{array}$ & 34 & 0.7 (0.5 to 0.9$)$ \\
\hline Patient declared dead & 26 & 0.5 (0.3 to 0.8$)$ \\
\hline Total & 5043 & 100 \\
\hline
\end{tabular}

Patients status at completion of mission

\begin{tabular}{|c|c|c|}
\hline Patient status unchanged & 2164 & 42.9 (41.5 to 44.3$)$ \\
\hline Patient status improved & 1993 & 39.5 (38.2 to 40.9$)$ \\
\hline $\begin{array}{l}\text { Patient status improved } \\
\text { significantly }\end{array}$ & 487 & 9.7 (8.9 to 10.5$)$ \\
\hline Patient's life saved & 47 & 0.9 (0.7 to 1.2$)$ \\
\hline Patient status deteriorated & 26 & 0.5 (0.3 to 0.8$)$ \\
\hline $\begin{array}{l}\text { Patient dead during the } \\
\text { mission }\end{array}$ & 31 & $0.6(0.4$ to 0.9$)$ \\
\hline Status missing & 295 & 5.9 (5.3 to 6.6$)$ \\
\hline Total & 5043 & 100 \\
\hline
\end{tabular}

applied to paediatric prehospital patients underline the significance of EMS providers' need for training and experience with critically ill children. Intubation and high-quality advanced airway management are considered crucial to critically ill patients and are key interventions provided by physician staffed EMS units. ${ }^{16}$ Since advanced airway management in small children is considered more challenging than in adults, ${ }^{18} 19$ and since it is so seldom needed in the prehospital setting, one could suggest that training should be obtained in other settings. An adequate experience with paediatric patients can probably only be achieved through in-hospital work rather than 'training on the job'.

The findings regarding monitoring were surprising: about one-third of all paediatric patients were not monitored with vital parameters, and only about one in five had all four vital parameters measured. This is in stark contrast to the child undergoing general anaesthesia where close to $100 \%$ of all cases are monitored to some degree. We argue that the findings in our study reflect the fact that monitoring in the prehospital setting is not based on standards of care but rely on the subjective clinical evaluation of the attending physician. Whether or not this has implications for patient safety is beyond the scope of this paper.

This study supports that the assertion that a critically ill child who is in need for life-saving intervention, is a rarity for the prehospital physician. However, these patients do exist and occasionally require critical interventions: responding physicians need to be experienced and skilled. When these patients are met, documentation should be done meticulously.

The large number of paediatric patients that are discharged at the scene following treatment (17\%), points towards the fact that many children are cared for without the need for admission to hospital. This could indicate both a low threshold for contacting the EMDC when a child in distress is concerned, but also a level of overtriage. It is possible that the accuracy of the dispatch system is not sufficient, and that further understanding of the dispatch element of paediatric case may lead to better usage of resources.

\section{CONCLUSIONS}

Prehospital paediatric contacts are uncommon. When they do occur, they frequently involve smaller children. Monitoring or at least documentation of monitoring, of basic vital parameters is infrequent in our material and may be an area for improvement. Advanced and potentially life-saving prehospital interventions provide a dilemma since these likely occur too infrequently to allow the prehospital emergency care providers to maintain technical skills solely in the prehospital environment.

\section{Limitations}

An important limitation of the present study is the application of a subjective measure of outcome. This may have given rise to reporting bias as the physician responsible for the mission performed was the one who made the initial assessment of the mission.

This is a retrospective and observational study with data originating from one geographical area. No conclusions can be made about the cause and relationships between the study parameters presented here, and comparison to other prehospital organisations must be done with caution. Larger and prospective studies are needed to study possible associations.

\section{Author affiliations}

${ }^{1}$ Department of Anaesthesiology and Intensive Care Medicine, Odense University Hospital, Odense, Denmark

${ }^{2}$ Department of Anaesthesia and Intensive Care Medicine, The Hospital of South West Jutland, Esbjerg, Denmark

${ }^{3}$ Department of Perioperative Services, Intensive Care Medicine and Pain management, Turku University Hospital, Turku Finnish University Association, Turku, Finland

${ }^{4}$ Paediatric Anesthesia and Intensive Care, Skåne University Hospital Lund, Lund, Skåne, Sweden

${ }^{5}$ Institution of Clinical Sciences, Lund University, Lund, Sweden

${ }^{6}$ Pediatric Anesthesia and Intensive Care, Department of Prehospital and Emergency Care, Queen Silvia's Children's Hospital, Sahlgrenska University Hospital, Goteborg, Sweden

${ }^{7}$ Mobile Emergency Care Unit, Odense University Hospital, Odense, Denmark ${ }^{8}$ Department of Regional Health Research, University of Southern Denmark, Odense, Denmark

Acknowledgements We thank Scandinavian Society for Anaesthesia and Intensive Care, and paediatric anaesthesia and intensive care fellowship programme, for supporting this study. 
Contributors MFO, AH, SAA, OT, JH and SM contributed to the conception and design of the study. MFO and SM contributed to the data handling and analysing of data. MFO, AH, SAA, OT, JH and SM provided contributions to the drafting of the manuscript and read and approved the final manuscript. MF0, AH, SAA, OT, JH and SM have agreed both to be personally accountable for their own contributions and to ensure that questions related to the accuracy or integrity of any part of the work, even ones in which the author was not personally involved, are appropriately investigated, resolved and the resolution documented in the literature.

Funding The authors have not declared a specific grant for this research from any funding agency in the public, commercial or not-for-profit sectors.

Competing interests None declared.

Patient consent for publication Not required.

Ethics approval The Danish Patient Safety Authority approved the study (Ref. no. 3-3013-3150/1). All data were handled in anonymised and retrospective form. Patients consent to inclusion or publication was not deemed necessary by The Danish Patient Safety Authority.

Provenance and peer review Not commissioned; externally peer reviewed.

Data availability statement Data are available upon reasonable request. Please contact Professor Søren Mikkelsenorchid-id: 0000-0002-5187-7027.

Open access This is an open access article distributed in accordance with the Creative Commons Attribution Non Commercial (CC BY-NC 4.0) license, which permits others to distribute, remix, adapt, build upon this work non-commercially, and license their derivative works on different terms, provided the original work is properly cited, appropriate credit is given, any changes made indicated, and the use is non-commercial. See: http://creativecommons.org/licenses/by-nc/4.0/.

\section{ORCID iDs}

Morten Føhrby Overgaard http://orcid.org/0000-0003-1946-3040

Søren Mikkelsen http://orcid.org/0000-0002-5187-7027

\section{REFERENCES}

1 Barker CL, Weatherall AD. Prehospital paediatric emergencies treated by an Australian helicopter emergency medical service. Eur J Emerg Med 2014;21:130-5.

2 Kaku N, Nitta M, Muguruma T, et al. Medical equipment deployment in pediatric emergency prehospital medical units in Japan. Pediatr Int 2018;60:93-5.

3 Heschl S, Meadley B, Andrew E, et al. Efficacy of pre-hospital rapid sequence intubation in paediatric traumatic brain injury: a 9-year observational study. Injury 2018;49:916-20.
4 Carlson JN, Gannon E, Mann NC, et al. Pediatric out-of-hospital critical procedures in the United States. Pediatr Crit Care Med 2015;16:e260-7.

5 Lo JY, Tani LY, Christensen M, et al. Outcomes after pediatric out-of-hospital cardiopulmonary interventions. Pediatr Emerg Care 2018;34:267-72.

6 Demaret P, Lebrun F, Devos P, et al. Pediatric pre-hospital emergencies in Belgium: a 2-year national descriptive study. Eur $J$ Pediatr 2016;175:921-30.

7 Babl FE, Vinci RJ, Bauchner $\mathrm{H}$, et al. Pediatric pre-hospital advanced life support care in an urban setting. Pediatr Emerg Care 2001;17:5-9.

8 Nevin DG, Green SJ, Weaver AE, et al. An observational study of paediatric pre-hospital intubation and anaesthesia in 1933 children attended by a physician-led, pre-hospital trauma service. Resuscitation 2014;85:189-95.

9 Weiss M, Vutskits L, Hansen TG, et al. Safe Anesthesia For Every Tot - The SAFETOTS initiative. Curr Opin Anaesthesiol 2015;28:302-7.

10 Weiss M, Becke K, Engelhardt T, et al. Concept of 10-N-Quality in Pediatric Anesthesia. SAFETOTS initiative, 2014. Available: www. safetots.org

11 Mikkelsen S, Lossius HM, Toft P, et al. Characteristics and prognoses of patients treated by an anaesthesiologist-manned prehospital emergency care unit. A retrospective cohort study. BMJ Open 2017;7:7.

12 Andersen MS, Johnsen SP, Sørensen JN, et al. Implementing a nationwide criteria-based emergency medical dispatch system. Scand J Trauma, Resusc Emerg Med 2013;21:1.

13 Ali S, Thomson D, Graham TAD, et al. High stakes and high emotions: providing safe care in Canadian emergency departments. Open Access Emerg Med 2017;9:23-6.

14 Guise J-M, Hansen M, O'Brien K, et al. Emergency medical services responders' perceptions of the effect of stress and anxiety on patient safety in the out-of-hospital emergency care of children: a qualitative study. BMJ Open 2017;7:e014057.

15 Ohashi-Fukuda N, Fukuda T, Doi K, et al. Effect of prehospital advanced airway management for pediatric out-of-hospital cardiac arrest. Resuscitation 2017;114:66-72.

16 Gerein RB, Osmond MH, Stiell IG, et al. What are the etiology and epidemiology of out-of-hospital pediatric cardiopulmonary arrest in Ontario, Canada? Acad Emerg Med 2006;13:653-8.

17 Ong $\mathrm{MEH}$, Osmond $\mathrm{MH}$, Gerein R, et al. Comparing pre-hospital clinical diagnosis of pediatric out-of-hospital cardiac arrest with etiology by coroner's diagnosis. Resuscitation 2007;72:26-34.

18 Lockey D, Crewdson K, Weaver A, et al. Observational study of the success rates of intubation and failed intubation airway rescue techniques in 7256 attempted Intubations of trauma patients by prehospital physicians. Br J Anaesth 2014;113:220-5.

19 Tarpgaard M, Hansen TM, Rognås L. Anaesthetist-provided prehospital advanced airway management in children: a descriptive study. Scand J Trauma Resusc Emerg Med 2015;23:61. 